\title{
Study to evaluate Association of Tobacco Chewing and Smoking with Semen Parameters
}

\author{
${ }^{1}$ Rishi R Vohra, ${ }^{2}$ Shivam Priyadarshi, ${ }^{3}$ Neeraj Aggarwal, ${ }^{4}$ Nachiket Vyas, ${ }^{5}$ Sher S Yadav, ${ }^{6}$ Vinay Tomar
}

\begin{abstract}
Introduction: Many studies have shown deleterious effects of tobacco abuse in any form on semen quality. We studied the association of tobacco chewing, smoking, and their combination on semen characteristics.
\end{abstract}

Materials and methods: Our study was performed on 216 normal asymptomatic healthy males (49 controls, 54 smokers, 55 tobacco chewers, and 58 consuming both) in the age group of 24 to 35 years. The effect on semen parameters was analyzed.

Results: Consuming both forms of tobacco individually and in combination had statistically significant effect on sperm morphology, progressive motility, and semen concentration. Other parameters show nonstatistically significant decline compared with controls.

Conclusion: As smoking and chewing tobacco negatively affect quality of semen, strategies should be developed to direct attention of the general population toward its effect on fertility status of male.

Keywords: Semen, Smoking, Tobacco.

How to cite this article: Vohra RR, Priyadarshi S, Aggarwal N, Vyas N, Yadav SS, Tomar V. Study to evaluate Association of Tobacco Chewing and Smoking with Semen Parameters. Int J Infertil Fetal Med 2017;8(3):97-100.

Source of support: Nil

Conflict of interest: None

Date of received: 09/07/2017

Date of acceptance: 21/08/2017

Date of publication: November 2017

\section{INTRODUCTION}

Tobacco in any form is known to cause detrimental effects on general health and on the reproductive system of males in particular. ${ }^{1}$ Smoking and chewing tobacco remain the main substance abuse worldwide. According to the statement issued by the World Health Organization (WHO), nearly one-third of all men older than 15 years smoke. ${ }^{2}$

\footnotetext{
${ }^{1}$ Resident, ${ }^{2,5,6}$ Senior Professor, ${ }^{3}$ Associate Professor, ${ }^{4}$ Professor

1-6Department of Urology, Sawai Man Singh Medical College Jaipur, Rajasthan, India

Corresponding Author: Rishi R Vohra, Resident, Department of Urology, Sawai Man Singh Medical College, Jaipur, Rajasthan India, Phone: +919958580617, e-mail: rrvohra@outlook.com
}

Even after running many programs for smoking cessation by governments the world over, men of reproductive age (20-39 years of age) make up nearly $46 \%$ of smokers. ${ }^{3}$ The prevalence of smoking is equal in all socioeconomic groups, while tobacco chewing is more prevalent in developing nations and lower socioeconomic strata. ${ }^{4}$

Reproductive capacity of men is dependent on multiple physiological functions as well as genetic factors. There are many ways in which smoking and chewing tobacco could affect male reproduction. Tobacco in any form can have a cytotoxic effect on spermatozoa, decreasing their number or by reduction in their ability to function. It can harm the testis and other parts of the male reproductive tract (e.g., accessory glands and ducts). Tobacco can also alter the reproductive hormone levels, which as a result can lead to impaired spermatogenesis, cytogenetic abnormalities, or mutations in spermatozoa that are passed on to offspring, potentially resulting in unfavorable reproductive and developmental outcomes, such as spontaneous abortions, congenital anomalies, or childhood cancer. Instead, tobacco constituents passed to the mother, either indirectly or by passive smoking, could adversely affect a developing fetus. Multiple studies have shown that abuse of tobacco in any form detrimentally affects sperm concentration, volume, motility, and morphology, and damages the deoxyribonucleic acid (DNA). ${ }^{5-10}$

Most previous studies of the relationship between smoking and semen quality have been performed in infertile and relatively small groups; therefore, large-scale studies reflecting the variety of smoking patterns, i.e., smoke form, smokeless form, and combination of smoke and smokeless form, among healthy men are needed. The aim of this study is to investigate the dose-response relationship of cigarette smoking, tobacco chewing, and their combination with conventional semen parameters.

\section{MATERIALS AND METHODS}

Adult nonalcoholic males between February 2016 and March 2017, attending the Sawai Man Singh Hospital aged 24 to 35 years, including 49 nonsmokers (who served as the controls), 54 smokers (bidi or cigarette), 55 tobacco chewers, and 58 who consumed smoke as well as smokeless form of tobacco were recruited for the study. The subjects were otherwise healthy without any reproductive tract infection and varicocele, and did 
not have a history of being in contact with any hazardous material. The study was approved by the Ethics Committee of our institute. The subjects enrolled for the study were informed and explained about the study. An informed consent was obtained from the participants. Before semen analysis, a questionnaire was distributed to obtain information on age, smoking habits, alcohol use (regular, irregular, or total abstinence), and use or abuse of other substances and drugs (yes or no). Patients were also asked about history of orchitis, testicular trauma, sexually transmitted disease, varicocele, inguinal hernia operation, and cryptorchism. Patients with age $<18$ years and $>47$ years, who refused to give consent, with history of $(\mathrm{h} / \mathrm{o})$ varicocele, $\mathrm{h} / \mathrm{o}$ occupational exposure to toxic chemicals or higher temperature, $\mathrm{h} / \mathrm{o}$ surgery for urogenital disease/any endocrine disorders, orchitis, testis trauma with hematoma, spinal injury, hernia repair, cryptorchidism, alcohol abuse (more than 7 packs per week), and patients with positive history of using drugs like cimetidine, antihypertensives, antidepressants, antipsychotics and chemotherapy, drugs abuse like morphine, cocaine, heroin, and marijuana were excluded from the study. Subjects with $\mathrm{h} / \mathrm{o}$ tobacco chewing or smoking for more than 5 years were included in our study.

After applying inclusion and exclusion criteria, 216 individuals with $\mathrm{h} / \mathrm{o}$ chewing or smoking tobacco products or both were analyzed and compared with healthy controls (49) for semen parameters, i.e., semen volume, motility, morphology, and semen concentration. Patients were grouped according to the form of tobacco intake, i.e., tobacco chewing (group I, $\mathrm{n}=55$ ), smoking (group II, $\mathrm{n}=54$ ), and both (group III, $\mathrm{n}=58$ ). The patients' age ranged from 24 to 35 years. Group I was further divided into two groups: Ia for tobacco chewers $<5$ times a day and group Ib for tobacco chewers $>5$ times. Similarly, group II was divided into persons smoking $<20$ cigarettes/bidi in a day as group IIa and smoking more than 20 cigarettes/bidi were categorized as group Illb. There was no confounding variable with respect to other relevant social habits or medical history.
Semen samples were collected by ejaculation after masturbation into a sterile container after 2 to 7 days of sexual abstinence. Analysis was performed within 2 hours after collection. Semen analysis consisted of determination of sample volume, sperm concentration, progressive motility, morphology, $\mathrm{pH}$, and concentrations of fructose. Standard clinical semen analysis was performed according to WHO criteria 2010. ${ }^{11}$

Data so collected were tabulated in an Excel sheet under the guidance of statistician. Data were analyzed using the IBM Statistical Package for the Social Sciences, version 20.0 (IBM Corp, Armonk, New York) for generation of descriptive as well as inferential statistics. The statistical significant difference among groups was determined by t-test, analysis of variance test, Kruskal-Wallis test, and Pearson correlation.

\section{RESULTS}

The sample consists of four groups, i.e., 49 controls, 54 smokers, 55 tobacco chewers, and 58 both tobacco chewers and smokers. The sociodemographic factors like age, weight, height, and body mass index (BMI) were statistically insignificant among the four groups. Semen morphology was affected mostly in persons who consume both tobacco and smoking with a mean of 19.05 followed by smokers 20.28 , tobacco chewers 21.18 , and control groups 23.94. When semen morphology was compared statistically among the four groups, it was found to be statistically significant $(p<0.05)$. Similar type of pattern was observed among the four groups in relation to semen progressive motility. Semen factors like volume, $\mathrm{pH}$, and fructose concentration were statistically insignificant among the four groups, whereas semen concentration was found to be statistically significant among the four groups (Table 1).

Table 2 shows that when factors like semen morphology and progressive motility were compared statistically based on the amount of tobacco and smoking consumption, it was found that those subjects who smoke more

Table 1: Demographic and semen parameters of different groups

\begin{tabular}{lllllc}
\hline Parameters & Control $(n=49)$ & Smoker $(n=54)$ & Tobacco chewer $(n=55)$ & Both $(n=58)$ & $p$-value \\
\hline Age & $25.34 \pm 3.81$ & $26.12 \pm 3.23$ & $25.94 \pm 3.52$ & $25.87 \pm 2.80$ & 0.676 \\
Weight & $62.98 \pm 5.80$ & $63.10 \pm 4.90$ & $62.48 \pm 5.40$ & $61.80 \pm 6.20$ & 0.6319 \\
Height & $166.06 \pm 5.05$ & $167.51 \pm 4.80$ & $166.90 \pm 5.30$ & $165.80 \pm 4.80$ & 0.2759 \\
BMI & $22.80 \pm 1.90$ & $22.58 \pm 2.10$ & $22.47 \pm 2.18$ & $22.54 \pm 3.30$ & 0.9161 \\
Semen volume (mL) & $3.46 \pm 0.70^{\mathrm{a}}$ & $3.43 \pm 0.60^{\mathrm{a}}$ & $3.45 \pm 0.68^{\mathrm{a}}$ & $3.41 \pm 0.58^{\mathrm{a}}$ & 0.9782 \\
Semen concentration (millions/mL) & $66.6 \pm 12.05^{\mathrm{a}}$ & $62.5 \pm 11.60^{\mathrm{a}}$ & $61.98 \pm 12.31^{\mathrm{a}}$ & $55.96 \pm 11.08^{\mathrm{b}}$ & 0.0001 \\
Morphology (\% normal forms) & $23.94 \pm 6.51^{\mathrm{a}}$ & $20.28 \pm 6.11^{\mathrm{b}}$ & $21.18 \pm 7.22^{\mathrm{b}}$ & $19.05 \pm 8.9^{\mathrm{c}}$ & 0.0065 \\
Progressive motility (\%) & $38.62 \pm 9.94^{\mathrm{a}}$ & $33.58 \pm 8.74^{\mathrm{b}}$ & $34.62 \pm 8.96^{\mathrm{b}}$ & $27.48 \pm 9.57^{\mathrm{c}}$ & $<0.001$ \\
pH & $7.3 \pm 0.4^{\mathrm{a}}$ & $7.5 \pm 0.3^{\mathrm{a}}$ & $7.4 \pm 0.3^{\mathrm{a}}$ & $7.1 \pm 0.6^{\mathrm{a}}$ & 0.08 \\
Fructose concentration (mol/L) & $54.8 \pm 40.5^{\mathrm{a}}$ & $51.1 \pm 38.7^{\mathrm{a}}$ & $51.78 \pm 39.79^{\mathrm{a}}$ & $49.32 \pm 37.28^{\mathrm{a}}$ & 0.9105 \\
\hline
\end{tabular}

*Analysis of variance test; categories with different alphabets signify statistical significance (Kruskal-Wallis test); annova is the test for obtaining $p$-value in more than two groups. Kruskal-wallis test is used for comparing two or more independent samples of equal or different sample sizes; ${ }^{a}$ samples are similar; ${ }^{b}$ sample is different from a; ${ }^{c}$ sample is different from a as well as b 
Association of Tobacco Chewing and Smoking with Semen Parameters

Table 2: Semen parameters in subgroups of smokers and tobacco chewers

\begin{tabular}{|c|c|c|c|c|c|}
\hline \multirow[b]{2}{*}{ Parameters } & \multirow[b]{2}{*}{ Control $(n=49)$} & \multicolumn{2}{|c|}{ Smoker $(n=54)$} & \multicolumn{2}{|c|}{ Tobacco chewer $(n=55)$} \\
\hline & & $<20$ & $>20$ & $<5$ & $>5$ \\
\hline Semen volume $(\mathrm{mL})$ & $3.46 \pm 0.70$ & $3.46 \pm 0.73$ & $3.4 \pm 0.64$ & $3.48 \pm 0.61$ & $3.42 \pm 0.79$ \\
\hline$p$-value & & 0.7494 & & 0.756 & \\
\hline Semen concentration (millions/mL) & $66.6 \pm 12.05$ & $64.69 \pm 10.59$ & $60.31 \pm 12.04$ & $62.98 \pm 11.87$ & $60.98 \pm 12.45$ \\
\hline$p$-value & & 0.1618 & & 0.5449 & \\
\hline Morphology (\% normal forms) & $23.94 \pm 6.51$ & $22.14 \pm 6.16$ & $18.42 \pm 6.21$ & $22.17 \pm 7.11$ & $20.19 \pm 7.46$ \\
\hline p-value & & 0.03 & & 0.04 & \\
\hline Progressive motility (\%) & $38.62 \pm 9.94$ & $36.92 \pm 7.69$ & $30.24 \pm 9.31$ & $36.56 \pm 8.02$ & $32.68 \pm 9.39$ \\
\hline$p$-value & & 0.005 & & 0.008 & \\
\hline $\mathrm{pH}$ & $7.3 \pm 0.4$ & $7.7 \pm 0.5$ & $7.3 \pm 0.3$ & $7.5 \pm 0.4$ & $7.3 \pm 0.2$ \\
\hline p-value & & 0.09 & & 0.11 & \\
\hline $\begin{array}{l}\text { Fructose concentration (mol/L) } \\
\text { p-value }\end{array}$ & $54.8 \pm 40.5$ & $\begin{array}{l}53.62 \pm 38.11 \\
0.6321\end{array}$ & $48.58 \pm 38.78$ & $\begin{array}{l}54.37 \pm 40.08 \\
0.6297\end{array}$ & $49.19 \pm 39.14$ \\
\hline
\end{tabular}

$p$-value: t-test

Table 3: Correlation among amount of smoking, tobacco chewing, and both forms with semen parameters

\begin{tabular}{lccc}
\hline & $\begin{array}{c}\text { Amount of } \\
\text { smoking }\end{array}$ & $\begin{array}{l}\text { Amount } \\
\text { of tobacco } \\
\text { chewing }\end{array}$ & $\begin{array}{c}\text { Amount of both } \\
\text { smoking and } \\
\text { tobacco chewing }\end{array}$ \\
Parameters & 0.012 & 0.011 & 0.14 \\
\hline $\begin{array}{l}\text { Semen volume }(\mathrm{mL}) \\
\text { Semen concentration } \\
\text { (millions/mL) }\end{array}$ & -0.402 & -0.372 & -0.438 \\
$\begin{array}{l}\text { Morphology (\% normal } \\
\text { forms) }\end{array}$ & & & \\
Progressive motility (\%) & -0.341 & -0.307 & -0.384 \\
pH & 0.19 & -0.271 & -0.329 \\
$\begin{array}{l}\text { Fructose concentration } \\
\text { (mol/L) }\end{array}$ & 0.15 & 0.28 \\
\hline
\end{tabular}

than 20 cigarettes per day and those who chew tobacco more than five times a day when compared with their counterparts have lower mean morphology and progressive motility $(\mathrm{p}<0.05)$.

It can be seen from Table 3 that there was a negative correlation between the amount of smoking, amount of tobacco chewing as well as amount of both smoking and tobacco chewing with semen concentration, morphology, progressive motility, and fructose concentration. Factors like semen volume, $\mathrm{pH}$, and fructose concentration were found to be statistically insignificant when correlated statistically with amount of smoking, amount of tobacco chewing, as well as amount of both smoking and tobacco chewing.

\section{DISCUSSION}

Many studies have suggested that cigarette smoking is associated with altered semen quality but studies regarding the effect of tobacco chewing as well as combined effect of tobacco chewing and smoking on semen quality in healthy men are few. The present is one of the few to find out the effect of smoking, smokeless tobacco, and combination of both by taking the sample of all the groups separately. Regardless of how tobacco is consumed, its adverse effects on disease and mortality rates are clear. In the present study, there is little difference between the four groups in association with factors like age, weight, BMI, and height, which eliminates the chances of confounding bias. Affected variables include motility, sperm concentration, total sperm count, semen volume, and morphology.

In the present study, semen volume was found almost similar among all the four groups and the same was supported by Ramlau-Hansen et al ${ }_{i}^{12}$ however, semen volume declined with an increasing number of cigarettes smoked and tobacco chewed, but no statistically significant differences were observed between the groups, which was similar to the findings reported by Pasqualotto et $\mathrm{al}^{13}$ (related to smoking) and Banarjee et $\mathrm{al}^{14}$ (related to tobacco chewing).

Statistically significant differences were observed between the groups in terms of sperm concentration, motility, or morphology in the present study. These variables were most affected in subjects who smoke as well as chew tobacco followed by smokers. The mean morphology and progressive motility was higher among smokers of 11 to 20 cigarettes per day than that among nonsmokers, which was statistically significant, whereas few other studies also report statistically nonsignificant trends. ${ }^{15}$ In fact, most of the studies reported either statistically significant dose-response relation between increased smoking and lowering of sperm concentration ${ }^{16}$ or a tendency toward decreasing sperm concentration with increase in smoking. ${ }^{17-19}$ Cigarette smoke as well as tobacco contains several chemical agents, many of which are carcinogenic or mutagenic. These agents affect the production and function of healthy normal sperm via different mechanisms. Smoking has also been found to affect accessory glands (prostate, epididymis, and seminal vesicles). ${ }^{20}$ Cigarette smoke may decrease male fertility through a direct effect on the testis and its 
ability to produce progressively motile sperm. Disturbance of the hypothalamo-pituitary-gonadal system ${ }^{21}$ and mild hypoxia caused by the disruption of the testicular microcirculation ${ }^{22}$ are possible explanations, but a direct toxic effect of the many chemical components in the cigarette smoke on the germinative epithelium is a more likely explanation. ${ }^{23}$ Oxidants in cigarette smoke are thought to damage sperm DNA, and smokers have more oxidative DNA damage in their sperm than do nonsmokers. ${ }^{24}$

As the present study is cross-sectional in design, we are unable to confirm a causal relationship of decreased semen quality with smoking, tobacco chewing, as well as consumption of both smoking and tobacco chewing, but when we stratified the participants into controls, smokers, tobacco chewers, and those who take both, we found a tendency toward decreasing sperm concentration and total sperm count with increasing tobacco smoke exposure, suggesting a harmful and partly irreversible effect of adult tobacco smoking. Naturally, large-scale, prospective studies have to be conducted to confirm this hypothesis of irreversibility.

\section{CONCLUSION}

Prevention and cessation programs should be directed toward specific high-risk groups. Strategies should be developed to direct the attention of the general public toward the possible relationship between tobacco consumption in any form and the incidence of male infertility. In addition, men who have a habit of tobacco consumption in any form should be advised about the potential adverse effects of their habit on sperm quality.

\section{REFERENCES}

1. Zhang ZH, Zhu HB, Li LL, Yu Y, Zhang HG, Liu RZ. Decline of semen quality and increase of leukocytes with cigarette smoking in infertile men. Iran J Reprod Med 2013 July;11(7):589-596.

2. Saleh RA, Agarwal A, Sharma RK, Nelson DR, Thomas AJ Jr. Effect of cigarette smoking on levels of seminal oxidative stress in infertile men: a prospective study. Fertil Steril 2002 Sep;78(3):491-499.

3. Trummer H, Habermann H, Haas J, Pummer K. The impact of cigarette smoking on human semen parameters and hormones. Hum Reprod 2002 Jun;17(6):1554-1559.

4. Sinha DN, Gupta PC, Ray C, Singh PK. Prevalence of smokeless tobacco use among adults in WHO South-East Asia. Indian J Cancer 2012 Oct-Dec;49(4):342-346.

5. Agarwal A, Hamamah S, Shekarriz M. Reactive oxygen species and fertilizing capacity of spermatozoa. Contracept Fert Sex 1994;22:327-330.
6. Arabi M, Moshtaghi H. Influence of cigarette smoking on spermatozoa via seminal plasma. Andrologia 2005 Aug;37(4): 119-124.

7. Armstrong JS, Rajasekaran M, Chamulitrat W, Gatti P, Hellstrom WJ, Sikka C. Characterisation of reactive oxygen species induced effects on human spermatozoal movement and energy metabolism. Free Radic Biol Med 1999 Apr;26(7-8): 869-880.

8. Aydos K, Guven MC, Can B, Ergun A. Nicotine toxicity to the ultrastructure of the testis in rats. BJU Int 2001 Oct;88(6): 622-626.

9. Christen AG, Glover ED. Smokeless tobacco: seduction of youth. World Smoking Health 1981;6:20-24.

10. Dikshit RK, Buch JG, Mansuri SM. Effect of tobacco consumption on semen quality of a population of hypofertile males. Fertil Steril 1987;48:334-336.

11. WHO laboratory manual for the examination and processing of human semen, 5 th ed. 2010;Ch 2.

12. Ramlau-Hansen $\mathrm{CH}$, Thulstrup AM, Aggerholm AS, Jensen MS, Toft G, Bonde JP. Is smoking a risk factor for decreased semen quality? A cross-sectional analysis. Human Reprod 2007;22(1);188-196.

13. Pasqualotto FF, Sobreiro BP, Hallak J, Pasqualotto EB, Lucon AM. Cigarette smoking is related to a decrease in semen volume in a population of fertile men. BJU Int 2006 Feb;97(2):324-326.

14. Banerjee A, Pakrashi A, Chatterjee S, Ghosh S, Dutta SK. Semen characteristics of tobacco user in India. Arch Androl 1993 Jan-Feb;30(1):35-40.

15. Oldereid NB, Rui H, Clausen OP, Purvis K. Cigarette smoking and human sperm quality assessed by laser-Doppler spectroscopy and DNA flow cytometry. J Reprod Fertil 1989 Jul;86(2):731-736.

16. Al Bader A, Omu AE, Dashti H. Chronic cadmium toxicity to sperm of heavy cigarette smokers: immunomodulation by zinc. Arch Androl 1999;43(2):135-140.

17. Marshburn PB, Sloan CS, Hammond MG. Semen quality and association with coffee drinking, cigarette smoking, and ethanol consumption. Fertil Steril 1989 Jul;52(1):162-165.

18. Vine MF. Smoking and male reproduction: a review. Int J Androl 1996 Dec;19(6):323-337.

19. Zhang JP, Meng QY, Wang Q, Zhang LJ, Mao YL, Sun ZX. Effect of smoking on semen quality of infertile men in Shandong, China. Asian J Androl 2000 Jun;2(2):143-146.

20. Pakrashi A, Chatterjee S. Effect of tobacco consumption on the function of male accessory sex glands. Int J Androl 1995 Oct;18(5):232-236.

21. Vermeulen A. Environment, human reproduction, menopause, and andropause. Environ Health Perspect 1993 Jul;101 (Suppl2): 91-100

22. Collin O, Kilter S, Bergh A. Tobacco smoke disrupts testicular microcirculation in the rat. Int J Androl 1995 Jun;18(3):141-145.

23. Zenzes MT. Smoking and reproduction: gene damage to human gametes and embryos. Hum Reprod Update 2000 Mar-Apr;6(2):122-131.

24. Horak S, Polanska J, Widlak P. Bulky DNA adducts in human sperm: relationship with fertility, semen quality, smoking, and environmental factors. Mutation Res 2003 May;537(1):53-65. 